\title{
Admission Glucose Levels and the Risk of Acute Kidney Injury in Nondiabetic ST Segment Elevation Myocardial Infarction Patients Undergoing Primary Percutaneous Coronary Intervention
}

\author{
Yacov Shacham ${ }^{a}$ Amir Gal-Oz ${ }^{b}$ Eran Leshem-Rubinow ${ }^{a} \quad$ Yaron Arbel $^{a}$ \\ Gad Keren $^{a}$ Arie Roth $^{a}$ Arie Steinvil ${ }^{a}$ \\ Departments of a Cardiology and ${ }^{b}$ Nephrology, Tel Aviv Sourasky Medical Center Affiliated \\ to the Sackler Faculty of Medicine, Tel Aviv University, Tel Aviv, Israel
}

\section{Key Words}

Hyperglycemia · Diabetes mellitus · Acute kidney injury · Acute myocardial infarction

\begin{abstract}
Background: Hyperglycemia upon admission is associated with an increased risk for acute kidney injury (AKI) in ST segment elevation myocardial infarction (STEMI) patients undergoing primary percutaneous coronary intervention (PCI). However, the relation of this association to the absence of diabetes mellitus (DM) is less studied. We evaluated the effect of acute hyperglycemia levels on the risk of AKI among STEMI patients without DM who were all treated with primary PCI. Methods: We retrospectively studied 1,065 nondiabetic STEMI patients undergoing primary PCI. Patients were stratified according to admission glucose levels into normal ( $<140 \mathrm{mg} / \mathrm{dl})$, mild (140-200 mg/dl), and severe (>200 mg/dl) hyperglycemia groups. Medical records were reviewed for the occurrence of AKI. Results: The mean age was $61 \pm 13$ years and $81 \%$ were males. Hyperglycemia upon hospital admission was present in 402 of 1,065 patients (38\%). Patients with severe admission hyperglycemia had a significantly higher rate of AKI compared to patients with no or mild hyperglycemia (20 vs. 7 and $8 \%$, respectively; $p=0.001$ ) and had a significantly greater serum creatinine change throughout hospitalization ( 0.17 vs. 0.09 and $0.07 \mathrm{mg} / \mathrm{dl}$, respectively; $p=0.04$ ). In multivariate logistic regression, severe hyperglycemia emerged as an independent predictor of AKI (OR = 2.46, 95\% CI 1.16-5.28; $p=0.018$ ). Conclusion: Severe admission hyperglycemia is an independent risk factor for the development of AKI among nondiabetic STEMI patients undergoing primary PCI.
\end{abstract}




\section{CardioRenal Medicine}

\begin{tabular}{l|l}
\hline Cardiorenal Med 2015;5:191-198 \\
\hline DOI: 10.1159/000430472 & $\begin{array}{l}\text { @ 2015 S. Karger AG, Basel } \\
\text { www.karger.com/crm }\end{array}$ \\
\hline
\end{tabular}

Shacham et al.: Admission Glucose Levels and the Risk of AKI in Nondiabetic STEMI Patients Undergoing Primary Percutaneous Coronary Intervention

\section{Introduction}

Acute kidney injury (AKI) frequently complicates the course of ST segment elevation myocardial infarction (STEMI) patients undergoing primary percutaneous coronary intervention (PCI) and is associated with adverse short- and long-term outcomes [1-4]. The worsening renal function may be a result of various factors including contrast-induced AKI [5-7], reduced renal perfusion, and other metabolic factors [8-10]. Elevated glucose levels upon hospital admission (acute hyperglycemia) are a common finding known to have a detrimental effect on the outcome of STEMI [11-13] patients, even in the absence of established diabetes mellitus (DM). Although previous studies have shown that elevated glucose levels increase the risk of contrast-induced nephropathy in patients undergoing elective PCI $[14,15]$, only limited data exist regarding the effect of hyperglycemia on AKI in STEMI patients undergoing primary PCI and its relation to the absence of known DM. In the present study, we evaluated the association of admission glucose levels with the occurrence of AKI in a large cohort of consecutive nondiabetic STEMI patients treated with primary PCI.

\section{Materials and Methods}

We performed a retrospective single-center observational study at the Tel Aviv Sourasky Medical Center, a tertiary referral hospital with a 24/7 primary PCI service. Included were all 1,452 consecutive patients admitted to the Cardiac Intensive Care Unit (CICU) between January 2008 and January 2014 with the diagnosis of acute STEMI. Patients who were treated either conservatively or by thrombolysis were excluded ( $\mathrm{n}=28$ ), as were 63 patients whose final diagnosis on discharge was other than STEMI (e.g. myocarditis or Takotsubo cardiomyopathy). Finally, 288 patients categorized as diabetic (using parameters described in previous reports $[10,13]$, e.g. if diabetes had previously been diagnosed by a physician or if they received medication to lower blood glucose levels) were also excluded. Information on admission glucose levels was unavailable for 8 patients, and thus they were omitted from the analysis. The final study population included 1,065 patients whose baseline demographics, cardiovascular history, clinical risk factors, treatment characteristics, and laboratory results were all retrieved from the hospital electronic medical records. Diagnosis of STEMI was established in accordance with published guidelines, including a typical chest pain history, diagnostic electrocardiographic changes, and serial elevation of cardiac biomarkers [16]. The study protocol was approved by the local institutional ethics committee with a waiver of informed consent.

Primary PCI was performed in patients with symptoms $\leq 12 \mathrm{~h}$ in duration as well as in patients with symptoms lasting $12-24 \mathrm{~h}$ in duration if the symptoms persisted at the time of admission. Time to coronary reperfusion was defined as the time from symptom onset (usually chest pain or discomfort), recorded upon admission, to the restoration of TIMI grade 3 flow in the infarct artery, as reported in the catheterization laboratory report. Critical-state patients were defined as those in whom intraaortic balloon counterpulsation was inserted or mechanically ventilated patients. The contrast medium used in the procedures was iodixanol (Visipaque, GE Healthcare, Ireland) or iohexol (Omnipaque, GE Healthcare). The left ventricular ejection fraction was assessed in all patients within the first $48 \mathrm{~h}$ of admission. The glucose value was determined on admission and was therefore nonfasting. Using the World Health Organization definition [17], hyperglycemia was defined as an admission glucose level of $\geq 140 \mathrm{mg} / \mathrm{dl}$. Patients with hyperglycemia were further categorized into mild $(140-200 \mathrm{mg} / \mathrm{dl}$ ) or severe $(>200 \mathrm{mg} / \mathrm{dl}$ ) hyperglycemia groups, similar to ranges used previously [11]. The serum creatinine ( $\mathrm{s} \mathrm{Cr}$ ) level was determined upon hospital admission and at least once a day during the CICU stay until discharge; it was available for all patients analyzed. The estimated glomerular filtration rate (eGFR) was estimated using the abbreviated Modification of Diet in Renal Disease equation [18]. Baseline renal insufficiency was categorized as an admission eGFR of $\leq 60 \mathrm{ml} / \mathrm{min} / 1.73 \mathrm{~m}^{2}$ [19]. AKI was determined using the AKI network (AKIN) criteria [20] and defined as an $\mathrm{sCr}$ rise $>0.3 \mathrm{mg} / \mathrm{dl}$ or an increase in $\mathrm{sCr} \geq 1.5$ times the baseline levels within $48 \mathrm{~h}$ of admission, compared with the admission sCr.

All data were summarized and displayed as means \pm standard deviations for continuous variables and as numbers (percentages) of patients in each group for categorical variables. The $\mathrm{p}$ values for the categorical variables were calculated with the $\chi^{2}$ test. Continuous variables were compared using the independent 


\section{CardioRenal Medicine}

Patients Undergoing Primary Percutaneous Coronary Intervention

Table 1. Baseline characteristics of 1,065 nondiabetic STEMI patients according to the presence of admission hyperglycemia

\begin{tabular}{|c|c|c|c|c|}
\hline \multirow[t]{2}{*}{ Variables } & \multicolumn{3}{|l|}{ Hyperglycemia } & \multirow[t]{2}{*}{$\mathrm{p}$} \\
\hline & none $(n=663)$ & mild $(n=320)$ & severe $(n=82)$ & \\
\hline Mean age $\pm S D$, years & $60 \pm 13$ & $63 \pm 13$ & $63 \pm 12$ & $<0.001$ \\
\hline Men & $553(83)$ & $256(80)$ & $63(77)$ & 0.209 \\
\hline Dyslipidemia & $271(41)$ & $130(41)$ & $31(38)$ & 0.867 \\
\hline Hypertension & $248(37)$ & $130(41)$ & $26(32)$ & 0.299 \\
\hline Smoker & $353(53)$ & $166(52)$ & $34(42)$ & 0.132 \\
\hline Family history of CAD & $123(19)$ & $50(16)$ & $4(5)$ & 0.006 \\
\hline Past myocardial infarction & $75(10)$ & $33(8)$ & $27(13)$ & 0.179 \\
\hline \multicolumn{5}{|l|}{ Number of narrowed coronary arteries ${ }^{\mathrm{a}}$} \\
\hline 1 & $323(48)$ & $137(43)$ & $34(42)$ & \multirow[t]{3}{*}{0.555} \\
\hline 2 & $193(29)$ & $103(32)$ & $26(32)$ & \\
\hline 3 & $147(23)$ & $79(25)$ & $22(26)$ & \\
\hline Critical state at admission & $23(3)$ & $33(8)$ & $50(23)$ & $<0.001$ \\
\hline Median time to reperfusion $\pm \mathrm{SD}$, min & $354 \pm 456$ & $300 \pm 420$ & $407 \pm 491$ & 0.01 \\
\hline Mean admission $\mathrm{CRP}^{\mathrm{b}} \pm \mathrm{SD}, \mathrm{mg} / \mathrm{l}$ & $12.4 \pm 27.3$ & $9.1 \pm 17.1$ & $22.7 \pm 38.1$ & 0.02 \\
\hline Mean $L V$ ejection fraction \pm SD & $49 \pm 7$ & $47 \pm 8$ & $46 \pm 9$ & $<0.001$ \\
\hline Mean peak creatine phosphokinase \pm SD & $1,108 \pm 1,253$ & $1,458 \pm 1,546$ & $1,710 \pm 1,963$ & $<0.001$ \\
\hline
\end{tabular}

Values are numbers with percentages in parentheses unless otherwise indicated. CAD = Coronary artery disease; CRP = C-reactive protein; LV = left ventricular. ${ }^{a}$ Narrowed artery was defined as a $>70 \%$ narrowing of lumen diameter. ${ }^{\mathrm{b}}$ Information on admission CRP level was available for only 518 patients.

sample t test or with ANOVA. The identification of the independent predictors of AKI was assessed using a logistic regression model in the enter mode. We adjusted for age, gender, hypertension, left ventricular ejection fraction, admission eGFR, critical state, time to reperfusion, as well as severe hyperglycemia. A twotailed $p$ value of $<0.05$ was considered significant for all analyses. All analyses were performed with the SPSS software (SPSS Inc., Chicago, Ill., USA).

\section{Results}

The study population included 1,065 patients (mean age $61 \pm 13$ years, $81 \%$ males). Hyperglycemia upon hospital admission was present in 402 of the 1,065 patients (38\%), of whom $320(30 \%)$ had mild and $82(8 \%)$ had severe hyperglycemia. The baseline characteristics of the patients according to the admission glucose levels are presented in table 1. Patients with admission hyperglycemia were more likely to be older, had a longer time to reperfusion, and were more likely to be in a critical state. Table 2 compares the occurrence of $\mathrm{AKI}$ and $\mathrm{sCr}$ changes between the admission glucose level groups. Patients having severe admission hyperglycemia had more AKI complicating the course of STEMI [ $20 \%$ vs. patients without (7\%) and with mild (8\%) hyperglycemia; $\mathrm{p}=0.001$ ] and had a significantly higher sCr change throughout hospitalization $[0.17 \mathrm{mg} / \mathrm{dl}$ vs. patients without $(0.09 \mathrm{mg} / \mathrm{dl})$ and with mild $(0.07 \mathrm{mg} / \mathrm{dl})$ hyperglycemia; $\mathrm{p}=0.04]$. No significant difference between the groups regarding the amount of contrast volume delivered during PCI was observed. Data on the contrast volume used were available for only 327 patients (30 had AKI); however, its amount during primary PCI did not differ between patients with or without AKI $(\mathrm{p}=$ 0.541). In a univariate analysis, the odds ratio (OR) for AKI development was 3.09 (95\% CI $1.63-5.64 ; \mathrm{p}=0.001$ ) when comparing patients with severe versus no hyperglycemia and 


\section{CardioRenal Medicine}

\begin{tabular}{l|l}
\hline \multicolumn{2}{l}{ Cardiorenal Med 2015;5:191-198 } \\
\hline DOI: 10.1159/000430472 & $\begin{array}{l}\text { C 2015 S. Karger AG, Basel } \\
\text { www.karger.com/crm }\end{array}$ \\
\hline
\end{tabular}

Shacham et al.: Admission Glucose Levels and the Risk of AKI in Nondiabetic STEMI Patients Undergoing Primary Percutaneous Coronary Intervention

Table 2. AKI, sCr changes, and intravenous contrast volume applied according to time to admission glucose

\begin{tabular}{|c|c|c|c|c|}
\hline \multirow[t]{2}{*}{ Variables } & \multicolumn{3}{|c|}{ Acute hyperglycemia } & \multirow[t]{2}{*}{$\mathrm{p}$} \\
\hline & no $(n=663)$ & mild $(n=320)$ & severe $(n=82)$ & \\
\hline AKI, n (\%) & $49(7)$ & $25(8)$ & $16(20)$ & $<0.001$ \\
\hline Admission eGFR, $\mathrm{ml} / \mathrm{min} / 1.73 \mathrm{~m}^{2}$ & $74 \pm 18$ & $68 \pm 17$ & $68 \pm 17$ & $<0.001$ \\
\hline Admission sCr, mg/dl & $1.11 \pm 0.22$ & $1.19 \pm 0.31$ & $1.21 \pm 0.31$ & $<0.001$ \\
\hline Peak sCr, mg/dl & $1.13 \pm 0.34$ & $1.21 \pm 0.53$ & $1.36 \pm 0.67$ & $<0.001$ \\
\hline sCr change in hospital, mg/dl & $0.09 \pm 0.25$ & $0.07 \pm 0.34$ & $0.17 \pm 0.48$ & 0.04 \\
\hline $\mathrm{sCr}$ at discharge, $\mathrm{mg} / \mathrm{dl}$ & $1.09 \pm 0.26$ & $1.16 \pm 0.36$ & $1.21 \pm 0.50$ & 0.01 \\
\hline Amount of contrast material ${ }^{\mathrm{a}}, \mathrm{ml}$ & $147 \pm 43$ & $141 \pm 51$ & $137 \pm 58$ & 0.541 \\
\hline
\end{tabular}

Values are means \pm SD unless otherwise indicated. ${ }^{\text {a }}$ Information on the amount of contrast volume was available for 327 patients.

Table 3. Binary logistic regression model for predicting AKI
Fig. 1. Frequency of AKI among 1,065 nondiabetic STEMI patients undergoing primary PCI, according to admission glucose levels $(p=0.001)$. The OR for AKI development was 3.09 (95\% CI 1.635.64; $\mathrm{p}=0.001$ ) when comparing patients with severe versus patients without hyperglycemia and $2.86(95 \%$ CI $1.45-5.65 ; \mathrm{p}=$ 0.004 ) for patients with severe versus patients with mild hyperglycemia.

\begin{tabular}{llll}
\hline Correlates & OR & $95 \% \mathrm{CI}$ & p value \\
\hline Age & 1.03 & $1.01-1.07$ & 0.04 \\
Gender & 0.884 & $0.46-1.65$ & 0.701 \\
Hypertension & 2.64 & $1.53-4.53$ & 0.001 \\
eGFR & 0.981 & $0.96-1.01$ & 0.078 \\
LV ejection fraction & 0.951 & $0.91-0.98$ & 0.001 \\
Critical state & 3.41 & $1.62-7.17$ & 0.001 \\
Time to reperfusion & 1.00 & $1.00-1.01$ & 0.177 \\
Severe hyperglycemia & 2.46 & $1.16-5.28$ & 0.018 \\
\hline
\end{tabular}

$\mathrm{LV}=$ Left ventricular.

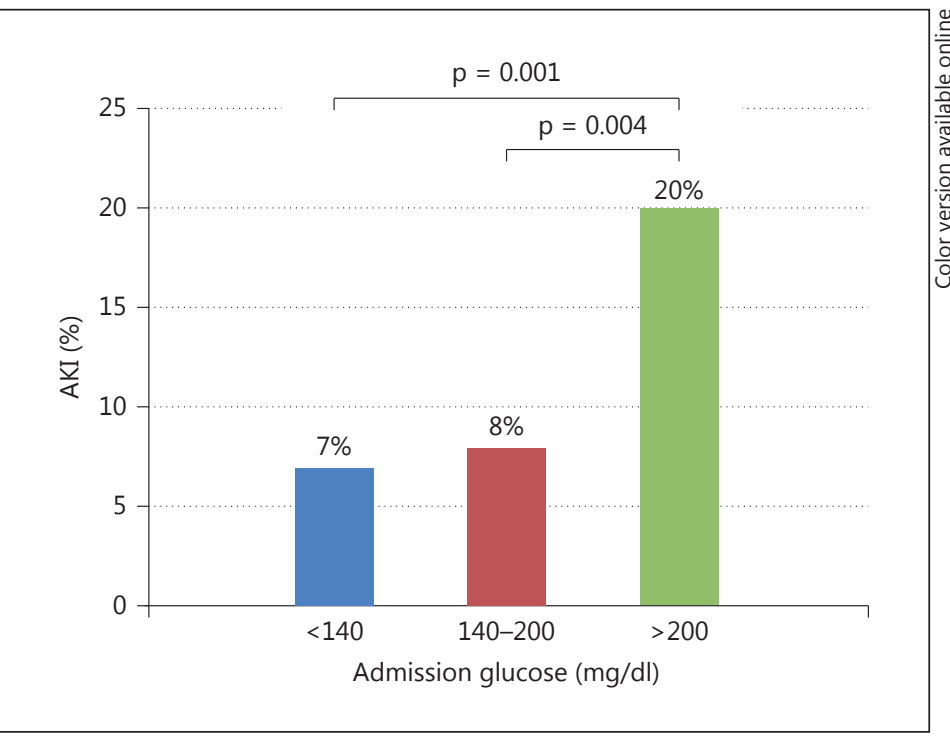


2.86 (95\% CI 1.45-5.65; $p=0.004)$ when comparing patients with severe versus mild hyperglycemia (fig. 1).

In a multivariate logistic regression model, severe hyperglycemia emerged as an independent predictor of AKI (OR = 2.46, 95\% CI 1.16-5.28; $\mathrm{p}=0.018)$. Other predictors of AKI included age, hypertension, left ventricular ejection fraction, and a critical state (table 3 ).

\section{Discussion}

This is the first trial to date assessing the association between admission glucose levels and the occurrence of AKI in a large cohort of consecutive nondiabetic STEMI patients undergoing primary PCI. Our findings suggest that severe hyperglycemia was common ( 8\%) upon admission and was significantly associated with AKI in those patients.

Hyperglycemia is common in patients with STEMI, even in the absence of a history of $\mathrm{DM}$, and has been identified as a major independent predictor of both in-hospital congestive heart failure and mortality in STEMI [11-13]. There are several explanations of the relation between hyperglycemia and the deterioration of renal function. Patients with acute hyperglycemia in our cohort had worse left ventricular function and higher creatine phosphokinase levels, both markers of a large infarct size. The sudden myocardial insult in STEMI often results in an acute reduction of cardiac output. This early hemodynamic deterioration may lead to reduced renal perfusion and, consequently, to kidney injury $[9,10]$. We have previously reported that reduced left ventricular systolic function is an independent predictor of AKI among STEMI patients undergoing primary PCI [21]. In addition, acute hyperglycemia was demonstrated to be associated with worse left ventricular systolic function in patients with first anterior STEMI [22]. Hyperglycemia may thus represent an epiphenomenon of the stress response, mediated by cortisol and catecholamines, whose release is elicited by the hemodynamic compromise or myocardial damage. Hyperglycemia may, however, exert a direct negative impact on renal function. The outer medullary region is particularly susceptible to ischemic injury because of its high metabolic activity and low prevailing oxygen tension [23]. The partial oxygen pressure of the outer medulla in the kidney is very low during normal function. Contrast media aggravate hypoxic injury to this region by increasing renal vascular resistance [24]. Hyperglycemia may lead to an increased production of oxygen free radicals with increased oxidative stress and suppressed flowmediated vasodilatation, inducing medullary hypoxia and ischemia, thus exacerbating the deleterious effect of contrast material $[25,26]$. Furthermore, acute hyperglycemia may induce osmotic diuresis, resulting in volume depletion and increasing the risk for prerenal azotemia and contrast toxicity. Indeed, the finding of no significant difference in the amount of contrast material used between those with and those without AKI in our results further emphasizes the importance of acute hyperglycemia in this setting. Our findings are in agreement with previous reports from studies performed on smaller STEMI cohorts. A recent report by Moriyama et al. [27] showed that patients having AKI following an acute myocardial infarction have higher admission glucose levels. In that report, however, nonSTEMI patients were also included, and not all patients were treated with primary PCI. Moreover, patients with AKI were more likely to be diabetic and had significantly higher hemoglobin $\mathrm{A}_{1 \mathrm{c}}$ levels. Marenzi et al. [10] demonstrated that acute hyperglycemia was associated with an increased risk for contrast-induced nephropathy following primary PCI and an increased 30-day mortality. Similar to our findings, they showed that the risk for AKI was elevated among nondiabetic rather than diabetic patients.

Our study carries important clinical implications. As the treatment of post-PCI AKI is rather limited, the main strategy is prevention of this complication. Early risk stratification 
before primary PCI offers a better opportunity to apply appropriate preventive management, even in the short emergent time frame of door-to-balloon.

Because admission glucose levels were found to be a powerful predictor of AKI, even in the absence of diabetes and independent of other clinical patient factors or potential confounders, risk prediction models for AKI after STEMI could be improved by including admission glucose levels. In those patients, the early implementation of prophylactic strategies aimed at preventing AKI or reducing its severity $[28,29]$ might also provide a significant clinical benefit.

Our study is consistent with findings of previous trials demonstrating that risk factors for AKI after emergent cardiac catheterization include age, critical state, and left ventricular ejection fraction. Contrary to previous reports [1-4], eGFR demonstrated only a strong trend for predicting AKI. Furthermore, we previously reported that time to reperfusion predicted AKI in STEMI patients undergoing primary PCI [30]; however, this variable was not significant in the current multivariate analysis. Importantly, these previous reports, including that on our cohort, included both diabetic and nondiabetic patients in the multivariate analysis. It can be assumed that in this specific population of nondiabetic STEMI patients undergoing primary PCI, severe hyperglycemia may be a stronger predictor of AKI than the above parameters.

We acknowledge several important limitations of our study. This was a single-center retrospective and nonrandomized observational study and may have been subject to bias, even though we included consecutive patients and attempted to adjust for confounding factors using the multivariate regression model. As in previous reports $[10,13]$, the diagnosis of DM was considered if it had been previously diagnosed by a physician or if patients received medication to lower blood glucose levels. However, since hemoglobin $\mathrm{A}_{1 \mathrm{c}}$ levels were not available for the patients, we cannot exclude that some of the nondiabetic patients with admission hyperglycemia actually had nondiagnosed diabetes. Information regarding the amount of contrast material used was available for only 327 patients. We showed, however, that in those patients, no significant changes were found regarding contrast volume between the groups. In addition, in a previous cohort studied by our group [30], contrast volume was not an independent predictor of AKI among STEMI patients undergoing primary PCI; thus, it was not included in the regression models. The definition of the AKIN criteria refers to $\mathrm{sCr}$ change within a time frame of $48 \mathrm{~h}$ [20]. As the change in $\mathrm{sCr}$ can lag beyond this period due to delayed effects of contrast material and drugs [5-7], worsening of renal function might have occurred following hospital discharge in some patients; thus, the true incidence of AKI described in our study may have been underestimated. No information existed regarding the amount of postprocedural intravenous fluid the patients received. In addition, information on left ventricular end-diastolic pressure during cardiac catheterization, which would also help determine the fluid status of patients at the time of acute STEMI, was not available, as this is not performed routinely in our catheterization laboratory during primary PCI. Finally, as data regarding concomitant use of renin/angiotensin blockers and diuretics throughout hospitalization were not available for many patients, their effect on AKI development could not be assessed.

In conclusion, in the present analysis, we have found that among nondiabetic STEMI patients undergoing primary PCI, severe hyperglycemia upon admission was significantly associated with AKI.

\section{Disclosure Statement}

The authors declare that they have no conflicts of interest. 


\section{CardioRenal Medicine}

\begin{tabular}{l|l}
\hline Cardiorenal Med 2015;5:191-198 \\
\hline DOI: 10.1159/000430472 & $\begin{array}{l}\text { @ 2015 S. Karger AG, Basel } \\
\text { www.karger.com/crm }\end{array}$ \\
\hline
\end{tabular}

Shacham et al.: Admission Glucose Levels and the Risk of AKI in Nondiabetic STEMI

Patients Undergoing Primary Percutaneous Coronary Intervention

\section{References}

1 Shacham Y, Leshem-Rubinow E, Steinvil A, Assa EB, Keren G, Roth A, Arbel Y: Renal impairment according to acute kidney injury network criteria among ST elevation myocardial infarction patients undergoing primary percutaneous intervention: a retrospective observational study. Clin Res Cardiol 2014;103:525-532.

-2 Goldberg A, Hammerman H, Petcherski S, Zdorovyak A, Yalonetsky S, Kapeliovich M, Agmon Y, Markiewicz W, Aronson D: Inhospital and 1-year mortality of patients who develop worsening renal function following acute ST-elevation myocardial infarction. Am Heart J 2005;150:330-337.

-3 Parikh CR, Coca SG, Wang Y, Masoudi FA, Krumholz HM: Long-term prognosis of acute kidney injury after acute myocardial infarction. Arch Intern Med 2008;168:987-995.

-4 Amin AP, Spertus JA, Reid KJ, Lan X, Buchanan DM, Decker C, Masoudi FA: The prognostic importance of worsening renal function during an acute myocardial infarction on long-term mortality. Am Heart J 2010;160: 1065-1071.

5 James MT, Samuel SM, Manning MA, Tonelli M, Ghali WA, Faris P, Knudtson ML, Pannu N, Hemmelgarn BR: Contrast-induced acute kidney injury and risk of adverse clinical outcomes after coronary angiography: a systematic review and meta-analysis. Circ Cardiovasc Interv 2013;6:37-43.

6 Gurm HS, Dixon SR, Smith DE, Share D, Lalonde T, Greenbaum A, Moscucci M; BMC2 (Blue Cross Blue Shield of Michigan Cardiovascular Consortium) Registry: Renal function-based contrast dosing to define safe limits of radiographic contrast media in patients undergoing percutaneous coronary interventions. J Am Coll Cardiol 2011;58:907-914.

7 Seeliger E, Sendeski M, Rihal CS, Persson PB: Contrast-induced kidney injury: mechanisms, risk factors, and prevention. Eur Heart J 2012;33:2007-2015.

-8 Koreny M, Karth GD, Geppert A, Neunteufl T, Priglinger U, Heinz G, Siostrzonek P: Prognosis of patients who develop acute renal failure during the first $24 \mathrm{~h}$ of cardiogenic shock after myocardial infarction. Am J Med 2002;112:115-119.

-9 Marenzi G, Assanelli E, Campodonico J, Lauri G, Marana I, De Metrio M, Moltrasio M, Grazi M, Rubino M, Veglia F, Fabbiocchi F, Bartorelli AL: Contrast volume during primary percutaneous coronary intervention and subsequent contrast-induced nephropathy and mortality. Ann Intern Med 2009;150:170-177.

10 Marenzi G, De Metrio M, Rubino M, Lauri G, Cavallero A, Assanelli E, Grazi M, Moltrasio M, Marana I, Campodonico J, Discacciati A, Veglia F, Bartorelli AL: Acute hyperglycemia and contrast-induced nephropathy in primary percutaneous coronary intervention. Am Heart J 2010;160:1170-1177.

11 de Mulder M, Cornel JH, van der Ploeg T, Boersma E, Umans VA: Elevated admission glucose is associated with increased long-term mortality in myocardial infarction patients, irrespective of the initially applied reperfusion strategy. Am Heart J 2010;160:412-419.

-12 Timmer JR, Hoekstra M, Nijsten MW, van der Horst IC, Ottervanger JP, Slingerland RJ, Dambrink JH, Bilo HJ, Zijlstra F, van't Hof AW: Prognostic value of admission glycosylated hemoglobin and glucose in nondiabetic patients with ST-segment-elevation myocardial infarction treated with percutaneous coronary intervention. Circulation 2011;124:704-711.

13 Goyal A, Mehta SR, Gerstein HC, Diaz R, Afzal R, Xavier D, Zhu J, Pais P, Lisheng L, Kazmi KA, Zubaid M, Piegas LS, Widimsky P, Budaj A, Avezum A, Yusuf S: Glucose levels compared with diabetes history in the risk assessment of patients with acute myocardial infarction. Am Heart J 2009;157:763-770.

14 McCullough PA, Adam A, Becker CR, Davidson C, Lameire N, Stacul F, Tumlin J; CIN Consensus Working Panel: Risk prediction of contrast-induced nephropathy. Am J Cardiol 2006;98:27K-36K.

-15 Turcot DB, Kiernan FJ, McKay RG, Grey NJ, Boden W, Perdrizet GA: Acute hyperglycemia: implications for contrast-induced nephropathy during cardiac catheterization. Diabetes Care 2004;27:620-621.

16 O'Gara PT, Kushner FG, Ascheim DD, Casey DE Jr, Chung MK, de Lemos JA, Ettinger SM, Fang JC, Fesmire FM, Franklin BA, Granger CB, Krumholz HM, Linderbaum JA, Morrow DA, Newby LK, Ornato JP, Ou N, Radford MJ, Tamis-Holland JE, Tommaso CL, Tracy CM, Woo YJ, Zhao DX, Anderson JL, Jacobs AK, Halperin JL, Albert NM, Brindis RG, Creager MA, DeMets D, Guyton RA, Hochman JS, Kovacs RJ, Ohman EM, Stevenson WG, Yancy CW: 2013 ACCF/AHA guideline for the management of ST-elevation myocardial infarction: a report of the American College of Cardiology Foundation/American Heart Association Task Force on Practice Guidelines. J Am Coll Cardiol 2012;61:e78-e140.

17 World Health Organization, International Diabetes Federation: Definition and Diagnosis of Diabetes Mellitus and Intermediate Hyperglycemia: Report of a WHO/IDF Consultation. Geneva, World Health Organization, 2006.

18 Levey AS, Bosch JP, Lewis JB, Greene T, Rogers N, Roth D: A more accurate method to estimate glomerular filtration rate from serum creatinine: a new prediction equation. Modification of Diet in Renal Disease Study Group. Ann Intern Med 1999;130:461-470.

-19 National Kidney Foundation (NKF) Kidney Disease Outcome Quality Initiative (K/DOQI) Advisory Board: K/ DOQI clinical practice guidelines for chronic kidney disease: evaluation, classification, and stratification. Am J Kidney Dis 2002;39:S1-S266.

20 Levin A, Warnock DG, Mehta RL, Kellum JA, Shah SV, Molitoris BA, Ronco C: Improving outcomes from acute kidney injury: report of an initiative. Am J Kidney Dis 2007;50:1-4.

21 Shacham Y, Leshem-Rubinow E, Gal-Oz A, Topilsky Y, Steinvil A, Keren G, Roth A, Arbel Y: Association of left ventricular function and acute kidney injury among ST-elevation myocardial infarction patients treated by primary percutaneous intervention. Am J Cardiol 2015;115:293-297. 


\section{CardioRenal Medicine}

Shacham et al:: Admission Glucose Levels and the Risk of AKI in Nondiabetic STEM Patients Undergoing Primary Percutaneous Coronary Intervention

-22 Ishihara M, Inoue I, Kawagoe T, Shimatani Y, Kurisu S, Nishioka K, Umemura T, Nakamura S, Yoshida M: Impact of acute hyperglycemia on left ventricular function after reperfusion therapy in patients with a first anterior wall acute myocardial infarction. Am Heart J 2003;146:674-678.

23 Persson PB, Patzak A: Renal haemodynamic alterations in contrast medium-induced nephropathy and the benefit of hydration. Nephrol Dial Transplant 2005;20(suppl 1):i2-i5.

-24 Kim SJ, Salem MR, Joseph NJ, Madayag MA, Cavallino RP, Crystal GJ: Contrast media adversely affect oxyhemoglobin dissociation. Anesth Analg 1990;71:73-76.

25 Kawano H, Motoyama T, Hirashima O, Hirai N, Miyao Y, Sakamoto T, Kugiyama K, Ogawa H, Yasue H: Hyperglycemia rapidly suppresses flow-mediated endothelium-dependent vasodilation of brachial artery. J Am Coll Cardiol 1999;34:146-154.

26 Monnier L, Mas E, Ginet C, Michel F, Villon L, Cristol JP, Colette C: Activation of oxidative stress by acute glucose fluctuations compared with sustained chronic hyperglycemia in patients with type 2 diabetes. JAMA 2006; 295:1681-1687.

27 Moriyama N, Ishihara M, Noguchi T, Nakanishi M, Arakawa T, Asaumi Y, Kumasaka L, Kanaya T, Miyagi T, Nagai T, Yamane T, Fujino M, Honda S, Fujiwara R, Anzai T, Kusano K, Goto Y, Yasuda S, Ogawa H: Admission hyperglycemia is an independent predictor of acute kidney injury in patients with acute myocardial infarction. Circ J 2014;78:1475-1480.

28 Patti G, Nusca A, Chello M, Pasceri V, D’Ambrosio A, Vetrovec GW, Di Sciascio G: Usefulness of statin pretreatment to prevent contrast-induced nephropathy and to improve long-term outcome in patients undergoing percutaneous coronary intervention. Am J Cardiol 2008;101:279-285.

29 Xinwei J, Xianghua F, Jing Z, Xinshun G, Ling X, Weize F, Guozhen H, Yunfa J, Weili W, Shiqiang L: Comparison of usefulness of simvastatin $20 \mathrm{mg}$ versus $80 \mathrm{mg}$ in preventing contrast-induced nephropathy in patients with acute coronary syndrome undergoing percutaneous coronary intervention. Am J Cardiol 2009;104:519-524.

-30 Shacham Y, Leshem-Rubinow E, Gal-Oz A, Arbel Y, Keren G, Roth A, Steinvil A: Relation of time to coronary reperfusion and the development of acute kidney injury after ST-segment elevation myocardial infarction. Am J Cardiol 2014;114:1131-1135. 